\title{
Minimally invasive procedure for repair of uterine isthmocele, a rare cause of infertility: a case report
}

\author{
Anusha Ginjupalli ${ }^{1,2 *}$, Joshi Suyajna D. ${ }^{1,2}$, \\ Nagarathna Suyajna Joshi ${ }^{1}$, Jayaprakash Patil ${ }^{1}$
}

\begin{abstract}
${ }^{1}$ Department of Gynecology and Laparoscopy, Geetha Fertility and Endoscopy Centre, Ballari, Karnataka, India
${ }^{2}$ Department of Obstetrics and Gynaecology, District Hospital, Ballari, Karnataka, India
\end{abstract}

Received: 22 April 2021

Accepted: 12 May 2021

\section{*Correspondence:}

Dr. Anusha Ginjupalli,

E-mail: anush617an@gmail.com

Copyright: (c) the author(s), publisher and licensee Medip Academy. This is an open-access article distributed under the terms of the Creative Commons Attribution Non-Commercial License, which permits unrestricted non-commercial use, distribution, and reproduction in any medium, provided the original work is properly cited.

\begin{abstract}
One of the known complications after caesarean delivery is uterine caesarean scar defect or isthmocele. Isthmocele is usually asymptomatic or may cause gynecological problems, such as menometrorrhagia, infertility, chronic abdominal/pelvic pain. Isthmocele may cause obstetrical sequalae like preterm delivery, uterine rupture, caesarean scar pregnancy or abnormal placental implantation. In the present case report, asymptomatic patient underwent laparoscopic surgery for isthmocele repair after shared decision-making and medical treatment have been evaluated. We suggested that isthmoplasty should be offered to women with symptoms or if it is causing infertility.
\end{abstract}

Keywords: Isthmocele, Caesarean scar defect, Laparoscopy, Isthmoplasty, Hysteroscopy

\section{INTRODUCTION}

The caesarean section rates (c-section) continues to increase around the world. ${ }^{1}$ The rates of caesarean deliveries in India steadily increased from $8 \%$ of deliveries in 2005 to $17 \%$ of deliveries in 2016 , even though the WHO recommends that rates of caesarean deliveries should not exceed $10-15 \%$ of total deliveries in any country. ${ }^{2}$ One of the most common gynecological aftereffects of caesarean section is a uterine scar with deficient healing, known as caesarean scar defect or isthmocele. ${ }^{3,4}$ Isthmocele is defined as a diverticulum on the anterior wall of the uterine isthmus, the cervical canal located near a caesarean delivery scar. ${ }^{5,6}$ Inadequate healing of myometrium at caesarean scar site contribute to the development of isomocele. Although, the presence of an isthmocele is usually asymptomatic, but can be cause of postmenstrual spotting and dark red or brown discharge, pelvic pain or infertility. ${ }^{6}$ The prevalence of symptomatic isthmocele after c-section is still unknown, with wide variations reported in different studies. ${ }^{7}$ The global frequency is observed between $6.2 \%$ and $36 \%$, with an average rate of $21.1 \% .^{9}$ Isthmocele could lead to complications such as infertility, placenta accrete or previa, scar dehiscence, uterine rupture, peripartum hysterectomy and caesarean scar ectopic pregnancy. The risk factors of isthmocele proven to date include retroflexed uterus and multiple caesarean sections. ${ }^{8}$

In many cases, the diagnosis of an isthmocele is incidental in patients who suffer from intermenstrual staining, dyspareunia, dysmenorrhea or secondary infertility. Diagnosis can be made by transvaginal ultrasound, pelvic MRI, hysterosonography and video hysteroscopy. With transvaginal ultrasound, the isthmocele appears as ananechoic zone with an isosceles triangle shape. ${ }^{10}$ Surgical excision of the isthmocele can be performed by hysteroscopic resection, laparoscopic resection and repair with or without robotic assistance, or repair of the isthmocele through vaginal approach. ${ }^{11}$ 


\section{CASE REPORT}

A 33 year old female patient who had been actively trying to conceive with a history of scar rupture during the previous c-section consulted our hospital regarding the prognosis in the next pregnancy. Her general and local examination and ultrasound revealed no abnormality. In pelvic MRI, at c-section scar, focal thinning of anterior wall of lower body of uterus measuring $5 \mathrm{~mm}$ with intact myometrium was observed (Figure 1A). The diagrammatic representation of the measurements of the isthmocele are represented (Figure 1B).

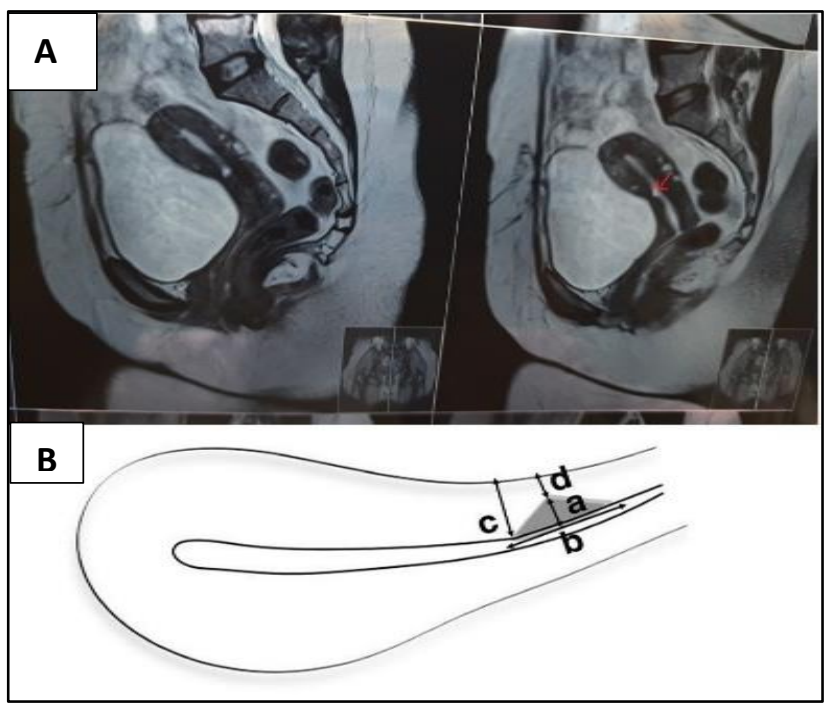

Figure 1: (A) Pelvic MRI: sagittal plane T2 weighted image showing the focal thinning of anterior wall of lower body of uterus at the site of scar measuring 5 mm with intact myometrium; (B) diagrammatic representation of isthmocele: $a=$ depth of the niche $(\sim 5$ $\mathrm{mm}), b=$ width of the base of niche $(\sim 9.6 \mathrm{~mm})$, c=adjacent myometrial thickness $(\sim 8.5 \mathrm{~mm})$, $\mathrm{d}=$ thickness of scar myometrium $(\sim 3.5 \mathrm{~mm})$.

\section{Procedure}

Patient opted for laparoscopic isthmocele repair. Before surgery, hysteroscopy was performed to identify the exact scar defect, that is, size and location. On hysteroscopy the defect of $5 \mathrm{~mm}$ was noted anteriorly just below the internal os. Laparoscopy was performed, uterovesical fold of peritoneum was identified and carefully dissected (Figure 2A). Bladder was mobilized in downward direction and the limits of the isthmocele are identified (Figure 2B). Edge of the isthmocele was delineated and the fibrotic tissue was then removed. Neoapproximation of edges was done in 2 layers with continuous sutures using V Loc no0 , engulfing the myometrial fibres that would tend to slide laterally (Figure 2C). At the end of the procedure, repeat hysteroscopy was performed to visualize the correction of defect and to check the continuity of the cervical canal with the uterine cavity (Figure 2D). Operating time was approximately 80 mins. Patient tolerated the procedure well. Patient discharged with tablet primolut N $10 \mathrm{mg}$ TDS for 7 days along with oral antibiotics to delay the menstruation and for the better healing.
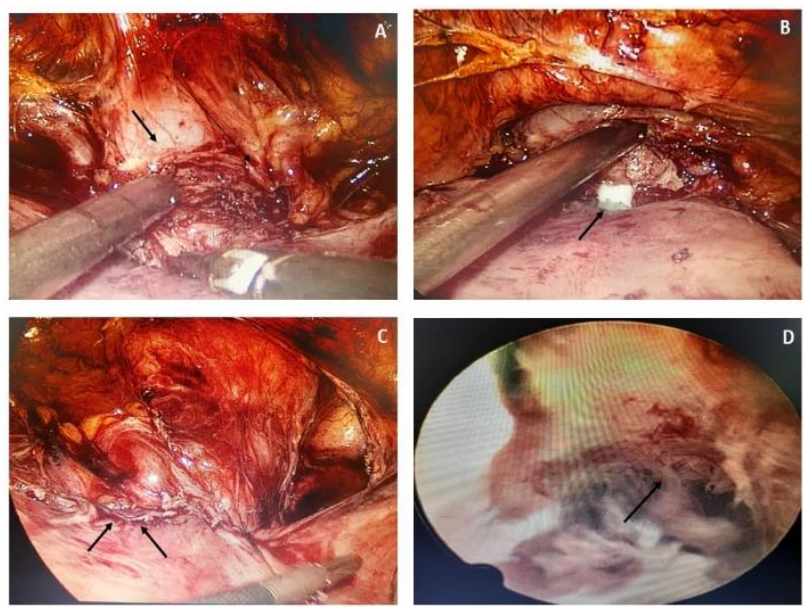

Figure 2: (A) Fibrosed tissue covering the isthmocele; (B) isthmocele identified on laparoscopy after resecting fibrosed tissue; $(\mathrm{C})$ laparoscopic view after isthmocele repair; (D) post procedure hysteroscopy showing the repaired defect.

\section{Result}

Isthmocele was repaired successfully. No major intraoperative or post-operative complications were observed.

\section{Follow up}

Relook hystero-laparoscopy was performed in the subsequent months after surgery revealed disappeared niche with normal myometrial thickness.

\section{DISCUSSION}

Isthmocele and associated gynaecological and obstetric problems are on the rise globally, which is alarming. It is estimated to be an isthmocele is present in approximately $60 \%$ of patients after a primary c-section and in $100 \%$ after 3 c-sections. ${ }^{12}$ Isthmocele is defined as indentations of the myometrium of atleast $2 \mathrm{~mm}$ (Figure 1B). Large niches occur less frequently., ${ }^{5,6}$ Although pre-pregnancy surgical repair of the defect are not routinely required for all the women, we believe prior surgical repair may be a safe option. ${ }^{14}$ Laparoscopic resection and resuturing the weakened scar aim at strengthening the scar and may ameliorate the chances of scar dehiscence, scar ectopic and fluid accumulation. Laparoscopic repair led to uterine bleeding improvement in $86 \%$ of cases and a pregnancy rate of $86 \% .{ }^{15}$ We suggest that in patients with isthmocele who are planning to conceive, surgical correction of the defect would prevent serious obstetrical complications. Several studies revealed the superiority of laparoscopic isthmocele repair compared with hysteroscopy for protection against abnormally invasive placenta, scar dehiscence and caesarean scar pregnancy. ${ }^{16}$ Awareness of 
isthmocele among gynaecologists and other practitioners who treat and diagnose abdominal and pelvic pain should be encouraged to prevent complications in pregnant patients with the defect.

\section{CONCLUSION}

The prevalence of isthmocele is projected to increase with the increase in the incidence of caesarean sections globally. Either hysteroscopy or laparoscopy could be used for the treatment of abnormal uterine bleeding, pelvic pain and subfertility secondary to this condition. Hysteroscopic surgery is a quick and cost effective procedure to improve the associated symptoms, but may not repair completely, while Laparoscopy is a minimally invasive procedure optimal for patients seeking fertility due to improved visualization of the defect and effective way to restore normal myometrial thickness. The decision to proceed with one technique or combined techniques depends on the characteristics of each case and the surgeon's skill and experience.

\section{Funding: No funding sources Conflict of interest: None declared \\ Ethical approval: Not required}

\section{REFERENCES}

1. Betran AP, Torloni MR, Zhang JJ, Gülmezoglu AM, WHO Working Group on Caesarean Section. WHOStatement on Caesarean Section Rates. BJOG. 2016;123(5):667-70.

2. Bhatia M, Banerjee K, Dixit P, Dwivedi LK. Assessment of variation in cesarean delivery rates between public and private health facilities in India from 2005 to 2016. JAMA Net Open. 2020;3(8):2015022.

3. Sisti G, Nasioudis D, Kanninen T, Sorbi F, Fambrini M. Risk factors for development of isthmocele following caesarean section. Minerva Ginecol. 2015;67(4):301-6.

4. Sardo ADS, Saccone G, McCurdy R, Bujold E, Bifulco G, Berghella V. Risk of cesarean scar defect following single vs double-layer uterine closure: systematic review and meta-analysis of randomized controlled trials. Ultrasound Obstet Gynecol. 2017;50(5):578-83.

5. Thurmond AS, Harvey WJ, Smith SA. Cesarean section scar as acause of abnormal vaginal bleeding: diagnosis by sonohysterography. J Ultrasound Med. 1999;18(1):13-6.
6. Vaate AJMBD, Brölmann HAM, Voet LFVD, Slikke JWVD, Veersema S, Huirne JAF. Ultrasound evaluation of the Cesarean scar: relation between a niche and postmenstrual spotting. Ultrasound Obstet Gynecol. 2011;37(1):93-9.

7. Tower AM, Frishman GN. Cesarean scar defects: an under recognized cause of abnormal uterine bleeding and other gynecologic complications. J Minim Invasive Gynecol. 2013;20(5):562-72.

8. Kaur A, Ahmad A. Isthmocele: a review of management options for this novel entity. Int J Human Heal Sci. 2019;3(3):127-33.

9. Vaate AJMBD, Voet LFVD, Naji O, Witmer M, Veersema S, Brölmann HAM, et al. Prevalence, potential risk factors for development and symptoms relatedto the presence of uterine niches following cesarean section: systematic review. Ultrasound Obstet Gynecol. 2014;43(4):372-82.

10. Nezhat C, Soliemannjad R, Razavi GM, Nezhat A Cesarean scar defect: what is it and how should it be treated? OBG Management. 2016;28(4):32-53.

11. LópezRivero LP, Jaimes M, Camargo F, LópezBayghen E. Successful treatment with hysteroscopy for infertility due to isthmocele and hydrometra secondary to cesarean section: a case report. World J Clin Cases. 2019;7(6):753-8.

12. Voet LF, Vervoort AJ, Veersema S, Vaate AJ, Brölmann HA, Huirne JA. Minimally invasive therapy for gynaecological symptoms related to a niche in the caesarean scar: a systematic review. BJOG. 2014;121(2):145-56

13. Nezhat C, Falik R, Li A. Surgical management of niche, isthmocele, uteroperitoneal fistula, or cesarean scar defect: a critical rebirth in the medical literature. Fertil Steril. 2017;107(1):69-71.

14. Szkodziak P, Stępniak A, Czuczwar P, Szkodziak F, Paszkowski T, Woźniak S. Uterine scar defect at 12 weeks gestation. J Obstet Gynaecol Can. 2014;36:759.

15. Tulandi T, Cohen A. Emerging Manifestations of Cesarean Scar Defect in Reproductive-aged Women. J Minim Invasive Gynecol. 2016;23(6):893-902.

16. Api M, Boza A, Gorgen H, Api O. Should cesarean scar defect be treated laparoscopically? A case report and review of the literature. J Minim Invasive Gynecol. 2015;22(7):1145-52.

Cite this article as: Ginjupalli A, Suyajna JD, Joshi NS, Patil J. Minimally invasive procedure for repair of uterine isthmocele, a rare cause of infertility: a case report. Int J Reprod Contracept Obstet Gynecol 2021;10:2511-3. 